\title{
Effect of the Fabrication Technique on Compressive Properties of Cu-PTFE Composites
}

\author{
Xuezhi Tang $\mathbb{D}$, Zhijun Wang $\mathbb{D}$, Jianping Yin, and Jianya Yi $\mathbb{D}$ \\ School of Mechatronic Engineering, North University of China, Taiyuan 030051, China \\ Correspondence should be addressed to Zhijun Wang; wzj@nuc.edu.cn
}

Received 7 February 2021; Revised 6 April 2021; Accepted 23 April 2021; Published 3 May 2021

Academic Editor: Baozhong Sun

Copyright (C) 2021 Xuezhi Tang et al. This is an open access article distributed under the Creative Commons Attribution License, which permits unrestricted use, distribution, and reproduction in any medium, provided the original work is properly cited.

\begin{abstract}
In this paper, the effect of manufacturing methods on the compressive properties of Cu-PTFE (polytetrafluoroethylene) composites was investigated. Two types of specimens were prepared through different manufacturing methods (extrusion forming and hot-press sintering). The specimens were tested using an electrohydraulic press and split-Hopkinson pressure bars for quasistatic loading and dynamic impact, respectively. The specific fracture processes were recorded by using a high-speed camera, and the failure microstructures of the specimens were analysed by SEM. According to the results, hot-press sintered specimens have consistently higher strength and toughness under dynamic compression than the extruded specimens, while the mechanical properties of hot-press sintered specimens are inferior to those of extruded specimens under quasi-static compression. The failure of extruded specimens is primarily caused by the elastic mismatch between the PTFE matrix and Cu particles, as well as the polymerisation of plastic pores, which leads to particle pullout. However, the cracks in the hot-press sintered specimens were caused by the shear deformation and interface sliding of the PTFE matrix, which led to matrix tearing.
\end{abstract}

\section{Introduction}

$\mathrm{Cu}-\mathrm{PTFE}$ (polytetrafluoroethylene) composites serve as an important benchmark for the current development of lowdensity materials, which can be used in military and civilian fields as reactive structural materials for target damage or barrier breaking $[1,2]$. Although the damage performance of low-density materials has previously been investigated $[3,4]$, little importance has been placed on the compressive properties of the material prior to experiments. However, different manufacturing methods can significantly affect the compressive properties of $\mathrm{Cu}-\mathrm{PTFE}$, and this is known to influence the deformation and fracture behaviours and affect the performance of shaped charges $[5,6]$.

Numerous simulations and experiments on the mechanical properties of PTFE materials have been conducted by scholars over the past few decades. Rae $[7,8]$ studied the material characterisation and properties of PTFE under tension and compression. Brown [9] investigated the effect of crystallinity on PTFE fracture. The results revealed that increasing the crystalline content of PTFE restricts the formation of fibres and increases the fracture toughness of JIC fitting. In addition, Poitou [10] compared the mechanical and physical characterisations of PTFE produced by high-velocity compaction and conventional sintering. The results showed that the density, crystal weight fraction, and wear properties of PTFE made by high-velocity compaction were improved. Canto [11] studied the deformation mechanisms of cold-compacted PTFE during sintering.

PTFE has become a common fluorine matrix for composite materials, adding metal to the PTFE matrix to modify it and form a new metal-PTFE composite has attracted the attention of many researchers in recent years. At present, the focus of research is adding metal into the PTFE matrices to obtain composite materials with specific properties. Many studies have shown that adding $\mathrm{Cu}$ to PTFE can optimise its friction and wear properties [12-14]. In fact, the inert $\mathrm{Cu}$-PTFE composite material can also be obtained by adding $\mathrm{Cu}$ powder to PTFE, which is largely used to form low-density, nonexplosive reactive armour.

The effects of particle size, composition, and processing technology on the mechanical properties of composites have 
long been studied, while the effects of manufacturing methods are not well understood. Borkowski [5] conducted experimental investigations on the formation and penetration efficiency of EFP charges with liners using a powder metallurgy method. He found that powder metallurgy is useful for the production of liners for EFP charges. Duan [6] studied the properties of a liner fabricated by sintering, and the experimental results showed that sintering thinned the wall and improved the density. Furthermore, the penetration performance of the sintered powder liner was better than that of its nonsintered counterpart. Therefore, the effect of fabrication technique on the compressive properties of $\mathrm{Cu}-$ PTFE requires further exploration.

In the present work, we use hot-press sintering to fabricate a dense $\mathrm{Cu}$-PTFE polymer from PTFE powder and compare it with specimens produced by extrusion forming. The dynamic and static mechanical properties of the two types of Cu-PTFE specimens are then tested. In addition, the instantaneous changes during dynamic compression are recorded by a high-speed camera, and the microstructures of the two composites are observed by SEM. The research contents of this paper can provide a reference for the creation of nonexplosive reactive armour using low-density materials.

\section{Experimental}

2.1. Raw Materials and Sample Fabrication. PTFE (average diameter: $220 \mu \mathrm{m}$; DP, Guangdong, China) and $\mathrm{Cu}$ (average diameter: $75 \mu \mathrm{m}$; Beijing, China) were used to fabricate the $\mathrm{Cu}$-PTFE sample; two types of specimens were prepared by different methods. Type A was cut from an extrudate (Figure 1(a)), while type B was cut from a rectangular sample (Figure 1(c)) produced by hot-press sintering.

The fabrication of the hot-press sintered samples is as follows: the two granular powders (PTFE/Cu weight ratio: $49.5 \% / 50.5 \%)$ were mixed several times using a motordriven blender. As shown in Figure 1(b), a graphite die was then filled with the mixed powder and placed in a vacuum oven under an argon atmosphere for hot-press sintering. The hot-press sintering process used in this investigation is shown in Figure 1(c); the direction of the pressure applied to the specimen during sintering is shown in Figure 1(c). Figure 1(d) shows the typical specimens used in subsequent compression tests; the theoretical density of all specimens is $3.5 \mathrm{~g} / \mathrm{cm}^{3}$.

2.2. Compression Experiments. Quasi-static compression tests were performed using a WDW-20 universal testing machine (MTS, Shanghai, China) at room temperature. Cylindrical specimens with dimensions of $8 \times 8 \mathrm{~mm}$ were loaded until failure at various crosshead speeds $(0.008,0.016$, 0.033 , and $0083 \mathrm{~s}^{-1}$ ).

The dynamic impact tests were completed using a highspeed camera and a split-Hopkinson pressure bar (SHPB) system, a schematic illustration of which is shown in Figure 2(a). The system consists of a launching device, velocity measuring device, incident bar, transmitted bar, bumper bar, and data acquisition system. Both the incident and transmitted bars were stainless steel cylinders with diameters and lengths of 12 and $1200 \mathrm{~mm}$, respectively. The bullet was $40 \mathrm{~mm}$ long and made of stainless steel. The bullet was powered by pressurised nitrogen, and the impact velocity as the bullet hit the incident bar was measured using a laser velocimetry device. The specimens of the same size in the quasi-static compression tests were also used in the dynamic impact test. The surfaces of the specimens were lightly lubricated with petroleum jelly to reduce friction.

The material properties are determined mainly by using strain gauges to measure the incident wave, reflected wave in the incident bar, and transmission pulse waveform in the transmitted bar; then, the stress-strain relationship of the specimen is derived from one-dimensional stress wave theory.

2.3. Basic Theory of the Split-Hopkinson Pressure Bar. The determination of the stress-strain behaviour of a material being tested in an SHPB is based on the principles of onedimensional elastic wave propagation within pressure loading bars $[15,16]$.

We use subscripts 1 and 2 to denote the incident and transmitted sides of the specimen, respectively. We then designate the strain in the bars as $\varepsilon_{i}, \varepsilon_{r}$, and $\varepsilon_{t}$, and the displacement at the end of specimens as U1 and U2 (input bar-specimen and specimen-output bar interfaces, respectively), as shown schematically in the magnified view of the specimen in Figure 3(a).

From the linear superposition principle of elastic waves, the displacement at interfaces 1 and 2 can be written as

$$
\begin{aligned}
& U_{1}=c_{b} \int_{0}^{t} \varepsilon_{i}-\varepsilon_{r} \mathrm{~d} \tau, \\
& U_{2}=c_{b} \int_{0}^{t} \varepsilon_{t} \mathrm{~d} \tau,
\end{aligned}
$$

where $c_{b}$ is the wave speed in the rod.

By definition, the average strain in the specimen is given by

$$
\varepsilon(t)=\frac{U_{1}-U_{2}}{l_{s}}=\frac{c_{b}}{l_{s}} \int_{0}^{t}\left(\varepsilon_{i}-\varepsilon_{r}-\varepsilon_{t}\right) \mathrm{d} \tau .
$$

Differentiating equation (3) with respect to time, the strain rate in the specimen is given by

$$
\dot{\varepsilon}=\frac{c_{b}}{l_{s}}\left(\varepsilon_{i}-\varepsilon_{r}-\varepsilon_{t}\right) \text {. }
$$

By definition, the forces in the two bars are

$$
\begin{aligned}
& F_{1}=A E\left(\varepsilon_{i}+\varepsilon_{r}\right), \\
& F_{2}=A E \varepsilon_{t},
\end{aligned}
$$

where $A$ is the cross-sectional area of the pressure bar and $E$ is Young's modulus of the bars (considered equal as the input and output bars are made of identical materials). From one-dimensional elastic wave theory, we know that the specimen is in force equilibrium, and, assuming that the 


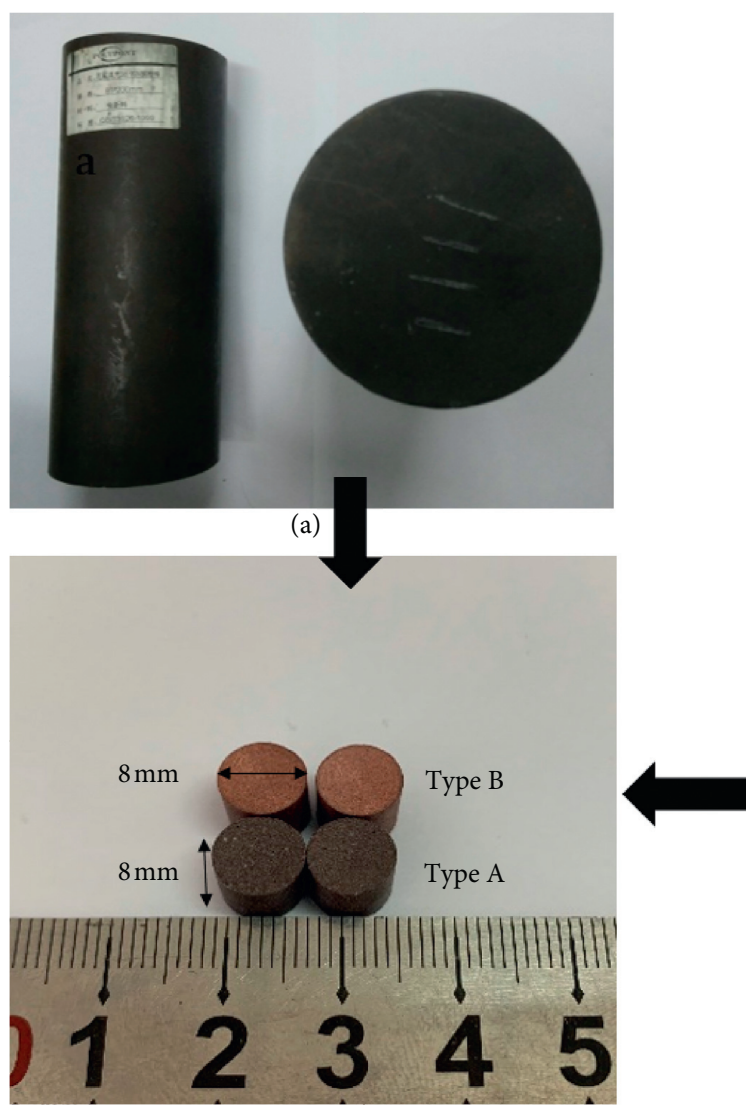

(d)
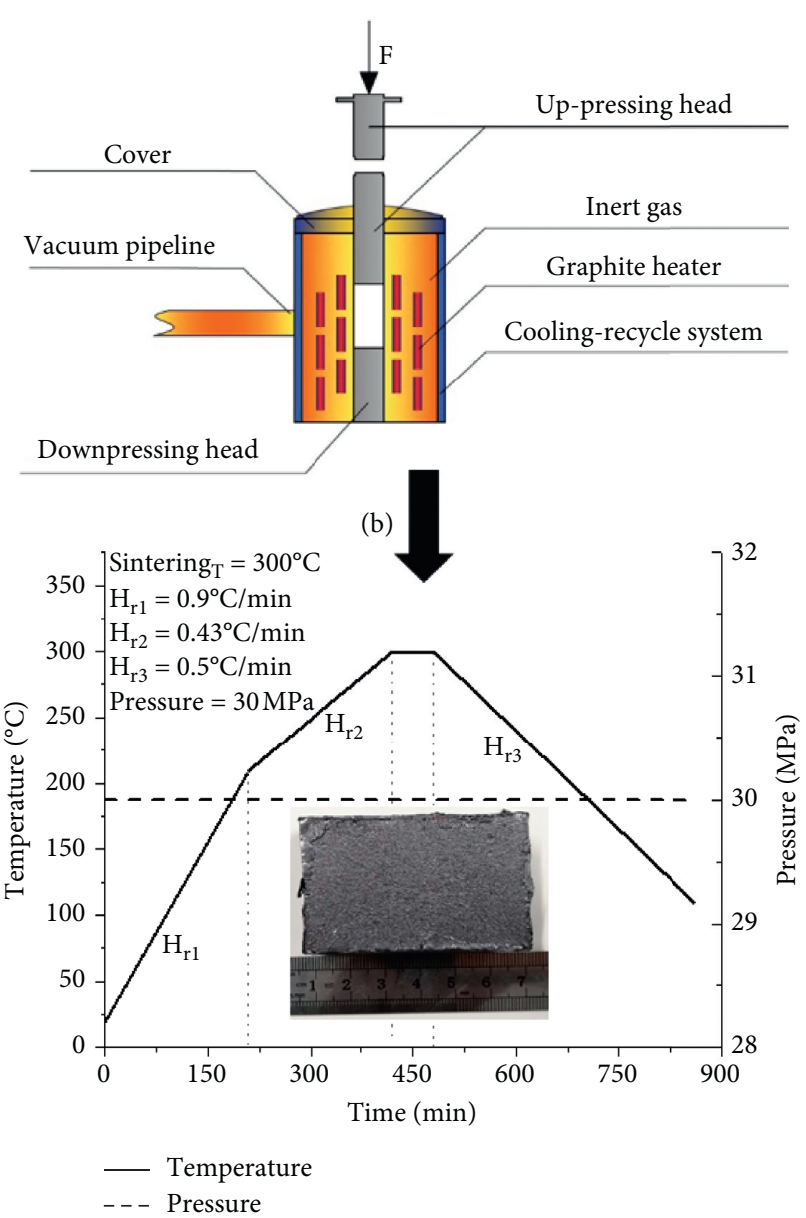

(c)

Figure 1: (a) Extrudate, (b) illustration of the hot-press sintering equipment, (c) hot-press sintering procedure, and (d) typical cylindrical specimens.

specimen deforms uniformly, a simplification can be made by equating the forces on each side of the specimen, that is, $F_{1}=F_{2}$. Comparing equations (5) and (6),

$$
\varepsilon_{i}+\varepsilon_{r}=\varepsilon_{t} .
$$

Substituting this criterion into equations (3) and (4) yields

$$
\begin{gathered}
\varepsilon(t)=2 \frac{c_{b}}{l_{s}} \varepsilon_{r} \mathrm{~d} \tau, \\
\dot{\varepsilon}=\frac{2 c_{b}}{l_{s}} \varepsilon_{r} .
\end{gathered}
$$

The stress was calculated from the strain gauge signal measure of the transmitted force divided by the instantaneous cross-sectional area $\left(A_{S}\right)$ of the specimen:

$$
\sigma(t)=\frac{A E \varepsilon_{t}}{A_{s}}
$$

where $\sigma(t)$ and $\varepsilon(t)$ are functions describing the engineering stress and strain of the material, respectively (assuming that the material is incompressible), and the relationship between the true stress and strain is given by

$$
\begin{aligned}
\sigma_{T} & =(1-\varepsilon(t)) \sigma(t), \\
\varepsilon_{T} & =-\ln (1-\varepsilon(t)) .
\end{aligned}
$$

The validity of the SHPB tests was verified by examining the incident and transmitted pressure bar data for the stress state equilibrium, as well as for a constant strain rate $[16,17]$. When the stress state of the entire specimen was uniform, the three- or two-wave stress oscillated equally around the one-wave stress. Figure 3(b) compares one-wave, threewave, and strain rate data as a function of the strain for an SHPB test conducted on the Cu-PTFE composite. In this illustration, the stress-strain curves obtained by the one- and three-wave stress methods exhibit very similar responses beyond $\sim 0.1$, verifying that the sample attained a uniform stress state.

\section{Results and Discussion}

3.1. Crystallinity of Cu-PTFE Composite Materials. A TG332 A microanalysis balance was used to determine the density of the samples at room temperature, and the average values of three samples were taken to determine the density of each specimen. The densities of the $\mathrm{Cu}$-PTFE specimens 


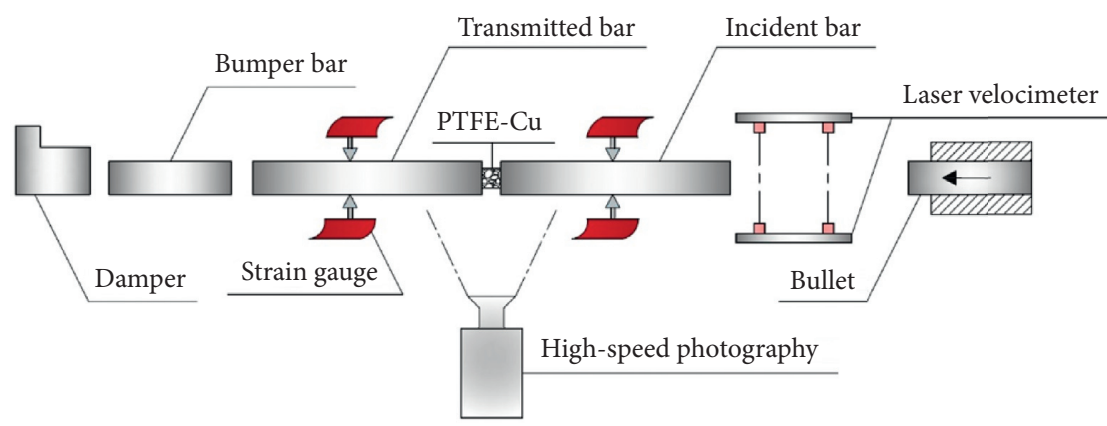

(a)

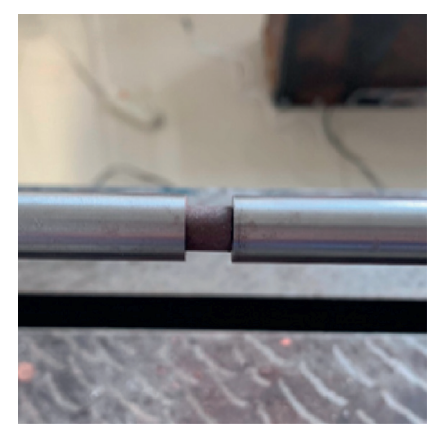

(b)

FIGURE 2: Split-Hopkinson pressure bar system: (a) schematic of the device and (b) detailed setting of specimens.
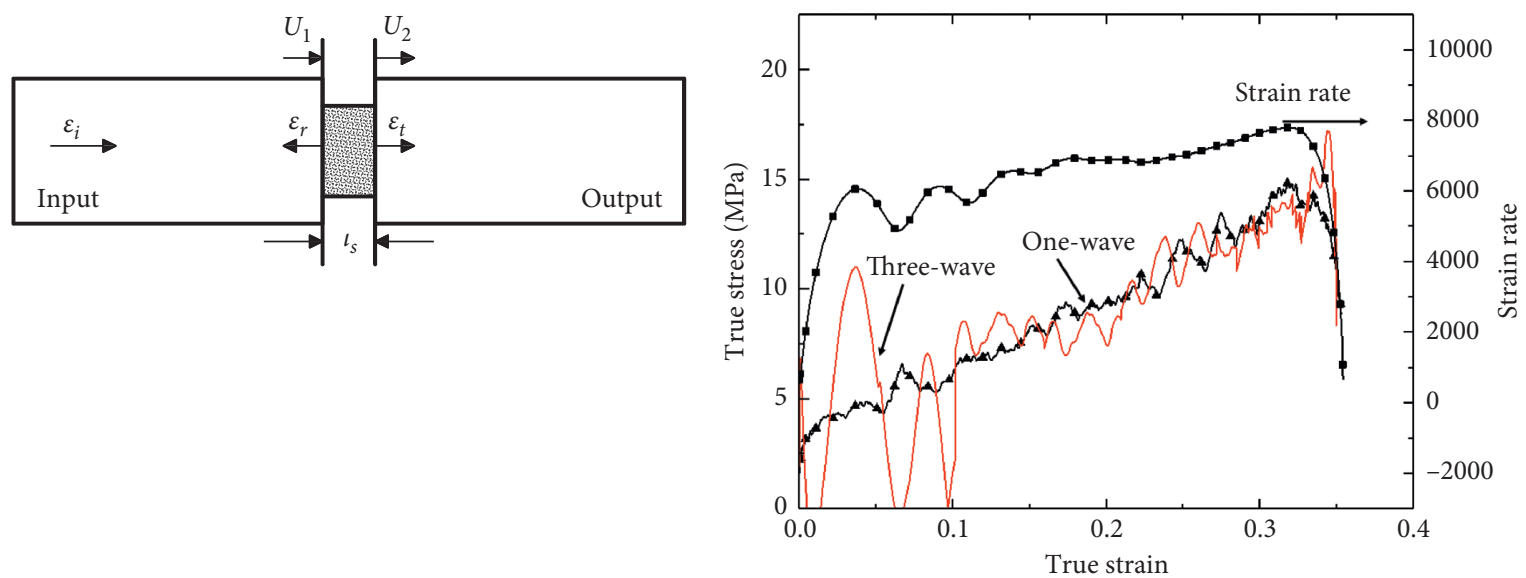

(a)

. (b)

FiguRE 3: (a) Expanded views of the input bar/specimen/output bar region. (b) One-wave versus three-wave analysis and strain rate of CuPTFE specimens.

produced by different methods were determined from Archimedes drainage measurements using the following equations:

$$
\begin{aligned}
\left(m_{1}-m_{2}\right) g & =\rho_{0} g V, \\
\rho & =\frac{m_{1}}{V},
\end{aligned}
$$

where $m_{1}$ and $m_{2}$ are the mass of the specimen in air and the liquid, respectively, $\rho_{0}$ is the density of the liquid, $V$ is the measured volume of the specimen, and $\rho$ is the measured density of the specimen.

The densification of materials has a significant influence on their microstructure and properties; improving the densification of materials will greatly improve their mechanical properties. The formula for calculating the densification, $\rho_{r}$, of the Cu-PTFE is

$$
\rho_{r}=\frac{\rho}{\rho_{m}} \times 100 \%,
$$

where $\rho_{m}$ is the theoretical density. The values reported in Table 1 were obtained from the above method. It can be seen from the table that the densification of type B specimens is higher than that of type A, which shows that the simultaneous application of temperature and pressure during the manufacturing process can promote separation and rearrangement of the particles. In addition, the grain boundary slip is driven more uniformly by the plastic flow of the particles, and the cohesive force between the particles is enhanced, which results in an increase in the density of the $\mathrm{Cu}$-PTFE composite.

Gaps and pores can be observed on the surface of the specimens, as shown in Figure 4, which are the initial defects caused by manufacturing. Very few gaps are present on the surface of the specimens prepared by hot-press sintering. However, there are pores at the edge of the specimen, largely on the PTFE matrix, as shown in Figure 4(a). There are two causes for the formation of pores. First, the powder surface contains a large amount of gas before hot-press sintering; this gas cannot be discharged during the moulding process, leading to defects in the matrix. The other reason is that the PTFE grains expand during heating and plastic deformation occurs, resulting in tightly packed grains. After the temperature and pressure decrease, some grains continue to deform, which leads to defects; thus, the actual density of the sample is lower than the theoretical density. 
TABle 1: Density of Cu-PTFE composites.

\begin{tabular}{lccc}
\hline Specimen & Measured density $\left(\mathrm{g} / \mathrm{cm}^{3}\right)$ & Theoretical density $\left(\mathrm{g} / \mathrm{cm}^{3}\right)$ & Densification $(\%)$ \\
\hline Type A (extrusion formed) & 3.38 & 3.5 & 96.57 \\
Type B (hot-press sintered) & 3.484 & 3.5 & 99.54 \\
\hline
\end{tabular}

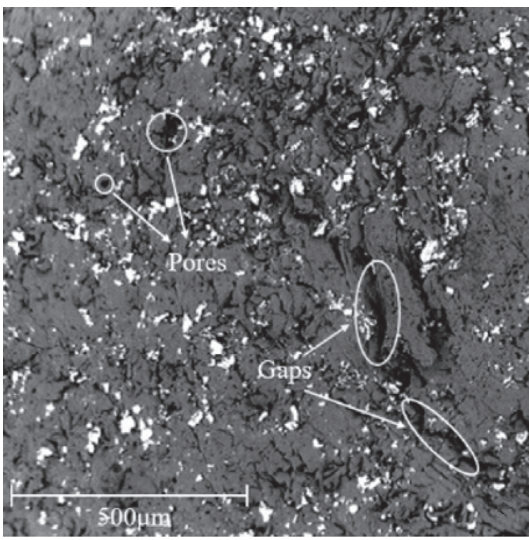

(a)

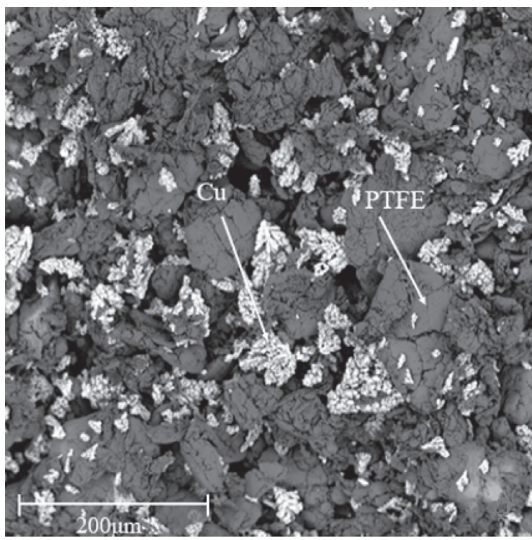

(b)

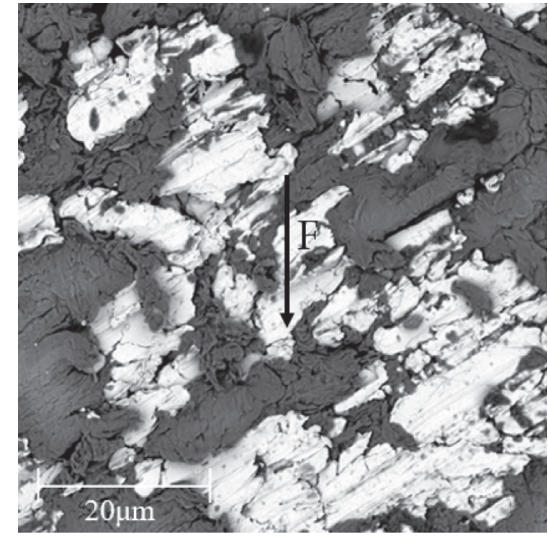

(c)

FIgUre 4: Typical SEM micrograph of surfaces of Cu-PTFE specimens: (a) type A, (b) type B precursor, and (c) type B.

Compared with the type B specimens, the surface of the extruded Cu-PTFE (Figure 4(b)) has many pores and microcracks. The pores primarily formed in the PTFE matrix, while the microcracks predominantly appeared at the joint between the PTFE and $\mathrm{Cu}$ particles. Microscopic cracks may develop into macroscopic cracks; thus, the properties of the $\mathrm{Cu}$-PTFE composite materials are affected. The measured density of the Cu-PTFE composites was also affected by the initial defects. There were many initial defects on the surface of the specimens prepared by extrusion forming, which led to the density of the type A specimens being lower than that of the type $\mathrm{B}$ specimens. The formation of a bonding surface between the grains during hot-press sintering does not cause shrinkage of the hot-press sintered body. An increase in specimen strength is an indication of sintering, whereas densification does not mark the beginning of the sintering process.

\subsection{Mechanical Properties}

3.2.1. Mechanical Response under Quasi-Static Compression. Figure 5 shows the true stress-strain curves of the two types of Cu-PTFE composites, and the corresponding mechanical properties are shown in Table 2. Based on these images, it can be observed that the stress-strain curves of the two types of specimens under quasi-static compression are very similar. All samples go through four stages: elastic, yield, strain hardening, and necking stages-which shows that all of the Cu-PTFE composites are both soft and tough elastoplastic materials. All specimens showed different degrees of barrel-shaped deformation as strain rate increased, although more serious failure behaviours were not observed. Type A and type B specimens displayed very little change during the elastic stage. After fitting the elastic stages of the specimens under different strain rates, it was found that the change in strain rate had little effect on the elastic modulus, as can be seen in Table 2. The elastic modulus of type A is approximately $162.5 \mathrm{MPa}$, which is $54.6 \%$ higher than that of type B $(73.75 \mathrm{MPa})$. However, the yield strength of type $B$ specimens is higher than that of type A. The yield and ultimate strengths of the two specimens increased with strain rate, while the fabrication method had no significant effect on the hardening modulus and failure strain.

According to these results, the densification of specimens prepared by hot-press sintering is better than those prepared by extrusion forming, although their mechanical properties are not clear from the quasi-static compression tests. A comparison of Figures 4(a) and 4(b) shows that both specimen types have pores and cracks on their surfaces. The interfacial bonding strength of the composites was directly affected by the initial defects, and well-bonded samples allow for effective stress transfer between the interfaces of particles. As shown in Figure 4(c), the $\mathrm{Cu}$ and PTFE particles of the specimens are tightly bonded after hot-press sintering, while the interface between the PTFE matrix and $\mathrm{Cu}$ particles was not well formed. The increase in the resistance of the stress transfer between the PTFE particles degrades the continuity and integrity of the mechanical properties of the specimens, which results in the ultimate strength of the type B specimens being lower than that of type A specimens. 


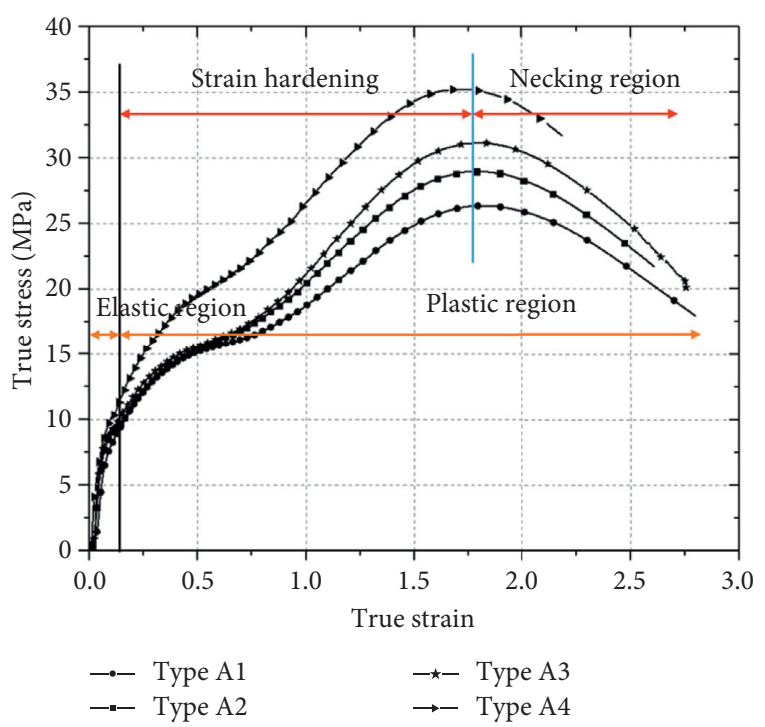

(a)

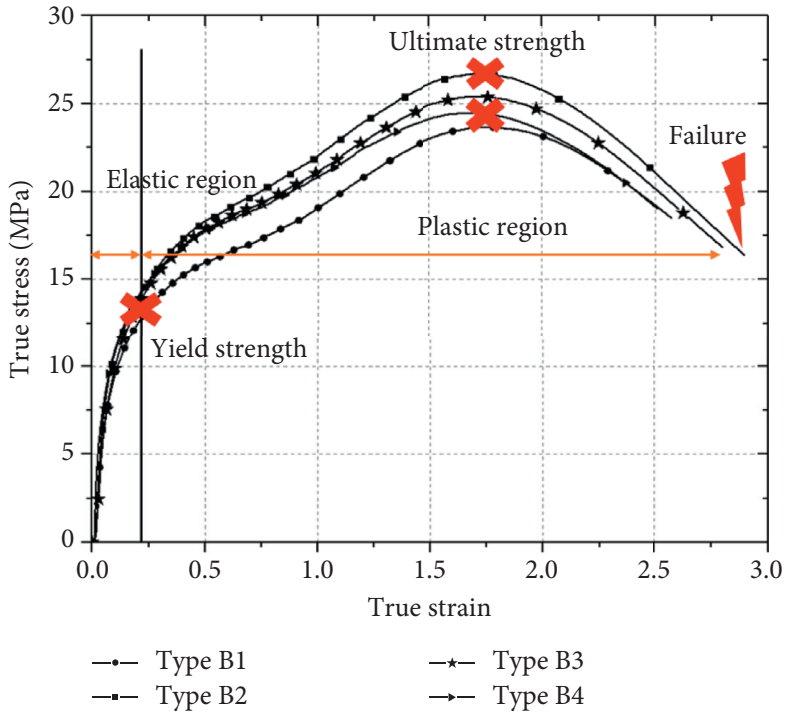

(b)

Figure 5: Comparison of true stress-strain curves for type A and type B Cu-PTFE at strain rates of 0.008 (A1/B1), 0.016 (A2/B2), 0.033 (A3/ B3), and $0.083 \mathrm{~s}^{-1}(\mathrm{~A} 4 / \mathrm{B} 4)$.

TABLE 2: Average mechanical parameters of $\mathrm{Cu}-\mathrm{PTFE}$ composites.

\begin{tabular}{|c|c|c|c|c|c|}
\hline Specimens & Elastic modulus (MPa) & Yield strength (MPa) & Hardening modulus (MPa) & Ultimate strength (MPa) & Failure strain \\
\hline A1 & 161 & 10.5 & 18.8 & 26.3 & 2.79 \\
\hline $\mathrm{A} 2$ & 157 & 10.9 & 20.4 & 28.9 & 2.60 \\
\hline A3 & 169 & 10.2 & 21.1 & 31.1 & 2.74 \\
\hline A4 & 163 & 11.6 & 26.7 & 35.2 & 2.18 \\
\hline B1 & 62 & 11.6 & 19.4 & 23.6 & 2.57 \\
\hline B2 & 80 & 12.9 & 22.4 & 26.6 & 2.89 \\
\hline B3 & 76 & 12.6 & 21.4 & 25.3 & 2.79 \\
\hline B4 & 77 & 13.3 & 21.1 & 24.4 & 2.50 \\
\hline
\end{tabular}

\subsubsection{Mechanical Response under Dynamic Compression.} The true stress-strain curves of type A and type B specimens with the same failure mode at different strain rates are compared in Figure 6. The true stress-strain curve was consistent with those observed by Feng [18].

In addition, it can be seen that there is no significant strain rate hardening effect in either type of specimen under dynamic compression. The yield strength of the specimens did not change regularly; however, the ultimate strength and failure strain increased with the strain rate. The specimens experienced progressive failure in three stages: plastic, splitting, and smash failure-as shown in Figure 6. The hot-press sintered samples exhibited greater toughness than their extruded counterparts. The following data were obtained by repeated dynamic compression tests on the specimens. Type A specimens underwent splitting failure at impact velocities greater than $15 \mathrm{~m} / \mathrm{s}$; smash failure occurred at impact velocities over $18 \mathrm{~m} / \mathrm{s}$. The type B specimens exhibited splitting and smash failures at impact velocities over 23.93 and $25 \mathrm{~m} / \mathrm{s}$, respectively. The elastic stage was not distinct, and the hardened state lasted for a long period under dynamic compression. The crossover of stress-strain curves was observed in the initial stage of plastic failure for type A specimens under different strain rates, but this phenomenon did appear in type B specimens, as shown in Figure 6. By comparing the stress-strain relationship between type A and type B specimens, it was found that the dynamic mechanical properties of type B samples were better than those of type A samples.

The mechanical properties of the two types of $\mathrm{Cu}-\mathrm{PTFE}$ materials under the three typical failure states are listed in Table 3. In combination with Figure 5, these data show that the strain rate of the two specimens increases with impact velocity. Greater kinetic energy is required to allow type B specimens to produce the same failure stage as type A specimens. Compared with the specimens at different strain rates, the ultimate strength of the material increases with the strain rate, but there is little variation in yield strength, with a maximum change of $28 \%$. In addition, the yield strength of splitting failure was higher than that of the other two failure states. The trend of yield and ultimate strengths of type B 


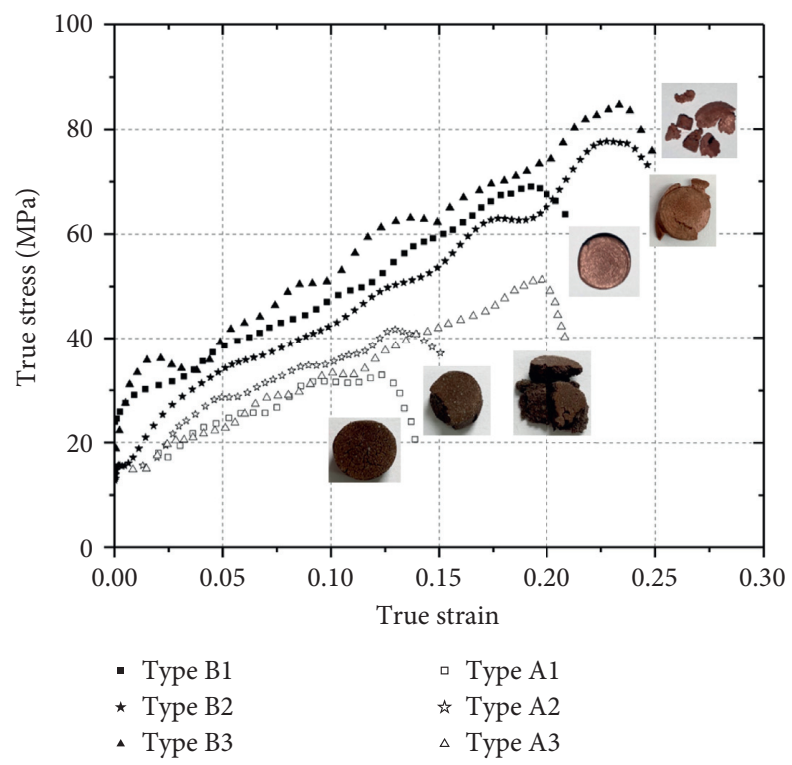

Figure 6: Comparison of type A and type B true stress-strain curves during SHPB at room temperature: plastic deformation (A1/B1), splitting failure (A2/B2), and smash failure (A3/B3).

TABLE 3: Parameters of Cu-PTFE specimens with different failure modes at dynamic compression test.

\begin{tabular}{|c|c|c|c|c|c|c|c|c|}
\hline \multirow[b]{2}{*}{ Failure mode } & \multicolumn{4}{|c|}{ Type A } & \multicolumn{4}{|c|}{ Type B } \\
\hline & $\begin{array}{c}\text { Impact } \\
\text { velocity }(\mathrm{m} / \mathrm{s})\end{array}$ & $\begin{array}{c}\text { Stain rate } \\
\left(\mathrm{s}^{-1}\right)\end{array}$ & $\begin{array}{l}\text { Yield strength } \\
(\mathrm{MPa})\end{array}$ & $\begin{array}{c}\text { Ultimate } \\
\text { strength }(\mathrm{MPa})\end{array}$ & $\begin{array}{c}\text { Impact } \\
\text { velocity }(\mathrm{m} / \mathrm{s})\end{array}$ & $\begin{array}{c}\text { Stain rate } \\
\left(\mathrm{s}^{-1}\right)\end{array}$ & $\begin{array}{l}\text { Yield strength } \\
(\mathrm{MPa})\end{array}$ & $\begin{array}{c}\text { Ultimate } \\
\text { strength }(\mathrm{MPa})\end{array}$ \\
\hline $\begin{array}{l}\text { Plastic } \\
\text { deformation }\end{array}$ & 13.7 & 1680 & 21.1 & 32.8 & 20.18 & 3060 & 31.7 & 67.3 \\
\hline Splitting failure & 15.99 & 1940 & 28.5 & 42.9 & 24.6 & 3483 & 27.1 & 82.4 \\
\hline Smash failure & 20.47 & 3290 & 20.5 & 51.2 & 25.38 & 3950 & 35.6 & 84.6 \\
\hline
\end{tabular}

specimens with different strain rates is approximately the same as those of type A specimens, while the yield of strength is approximately $23 \%$. The yield and ultimate strengths of type B are $42 \%$ and $51 \%$ higher than those of type $A$, respectively.

3.3. Failure Microstructure Analysis. The mesoscale characteristics of the two types of Cu-PTFE composite materials after quasi-static compression were compared and are shown in Figure 7. As presented in Figures 7(a) and 7(d), cracks and pores caused by quasi-static compression are observed on the cylindrical surfaces of the type A and type B specimens. It is worth noting that more cracks and pores have formed on the surface of the type A specimen, with pores appearing near the edge of the surface. As shown in Figure 7(b), the cracks typically appear near the phase boundary, passing through the PTFE and $\mathrm{Cu}$ particles. The two types of grains produced different elastic strains under external pressure owing to the different elastic moduli of the particles; this caused cracks to appear at the interface between the grains. The external pressure was higher than the ultimate strength of the PTFE matrix, resulting in microcracks within the PTFE.

It is also worth noting that there are PTFE fibres between the microcracks in the matrix, which can effectively prevent further crack propagation. The cracks of the type B specimens primarily extend along the edge of the pores in the PTFE matrix, as shown in Figure 7(f). The type B specimen was crystallised at low temperatures, and the cracks were largely caused by the shear deformation and boundary sliding of the PTFE matrix grains. The elastic modulus of the type B specimen is lower than that of type A because there are no PTFE fibres between the cracks, so the specimen is more prone to deformation under external force. It can be observed from Figure 7 (c) that the diameter of the pores on the surface of the type A specimen became larger after constant pressure, and the PTFE hole edge contacts the $\mathrm{Cu}$ particles. In addition, the stress field between the pores produces an interaction, leading to the aggregation of the plastic pores. However, there was no aggregation of pores on the surface of the type B specimens, and the pores appeared independently on the PTFE matrix, as shown in Figure 7(e). This resulted in complete and continuous load transfer between the PTFE and $\mathrm{Cu}$ particles, which also explains the higher yield strength of the type B specimens.

The mesostructure characteristics of the two types of $\mathrm{Cu}$-PTFE composite materials after dynamic compression are compared and shown in Figure 8. The particle pull-out phenomenon can clearly be observed on the fracture surface of the type A specimen, and the pits are smooth and intact after dynamic impact, as shown in Figures 8(a) and 


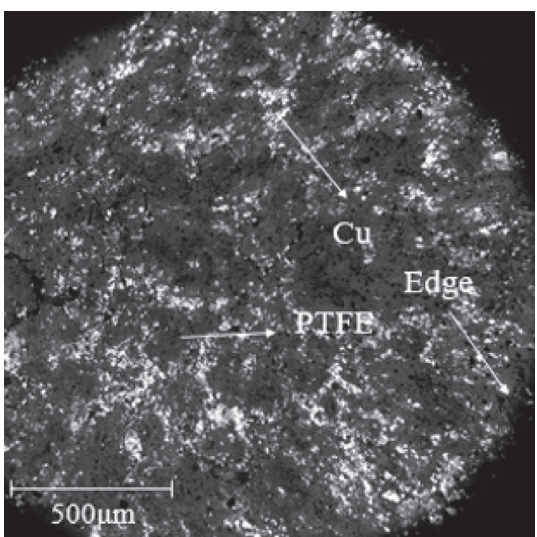

(a)

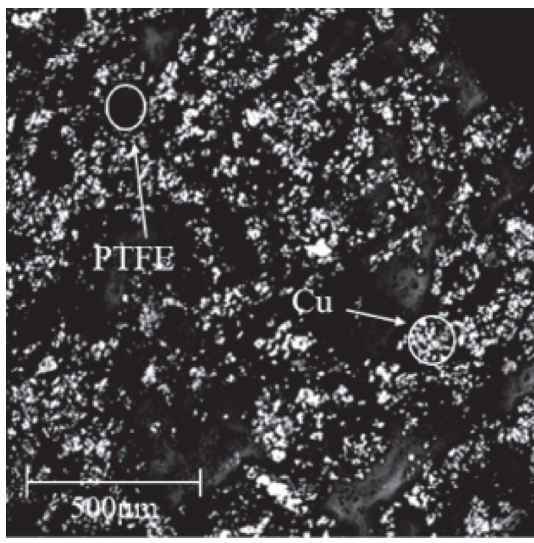

(d)

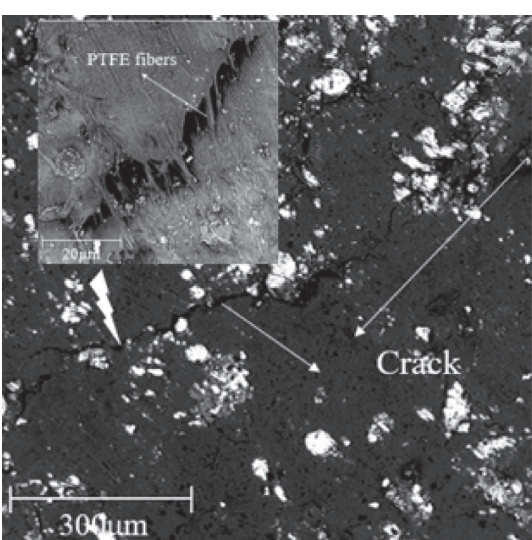

(b)

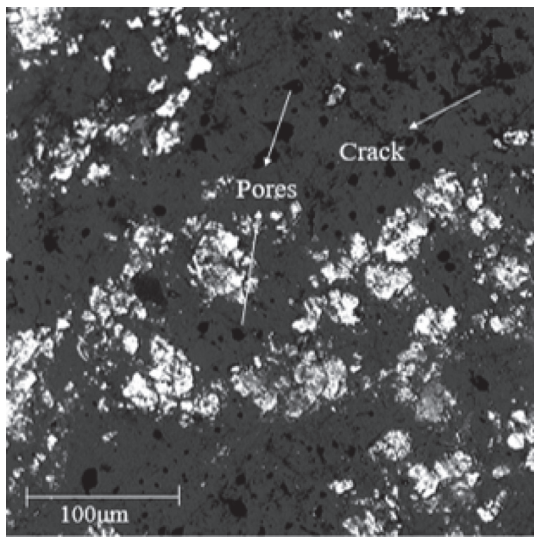

(e)

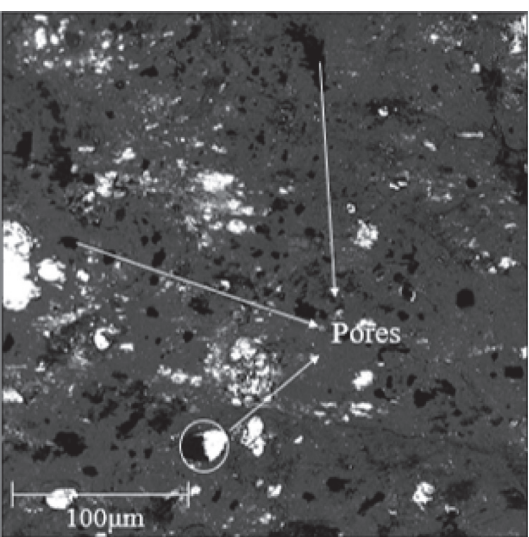

(c)

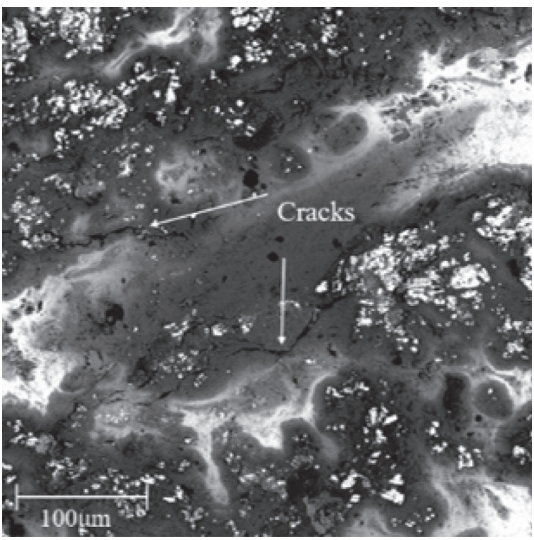

(f)

Figure 7: Mesoscale characteristics of Cu-PTFE specimens after quasi-static compression: (a-c) type A; (d-f) type B.

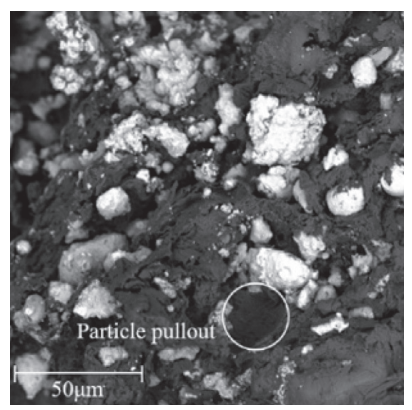

(a)

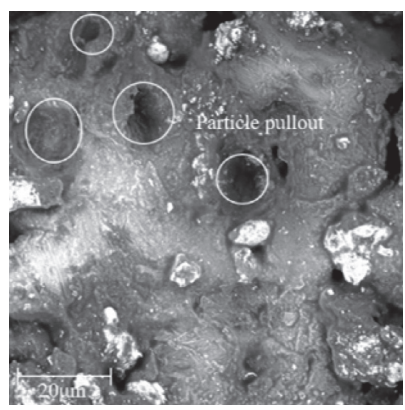

(b)

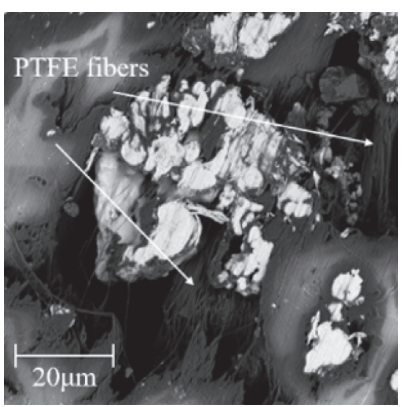

(c)

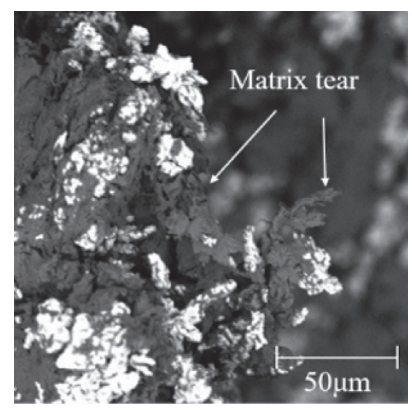

(d)

Figure 8: Mesostructure of Cu-PTFE specimens after dynamic compression: (a, b) type A; (c, d) type B.

8(b). Some PTFE fibres appear on the fracture surface of type $\mathrm{B}$, which connect from one side of the crack through the $\mathrm{Cu}$ particles to the PTFE on the other side, as presented in Figure 8(c). The $\mathrm{Cu}$ particles in the type $\mathrm{B}$ specimens were wrapped by PTFE particles, while the two types of particles in type A were interembedded by mechanical bonding. A PTFE matrix tear appeared on the fracture surface of the type B specimens, as shown in Figure 8(d), which is different from the fracture state of type A specimens. The bonding and distribution types of the matrix and metal particles depend on the fabrication method, which leads to significant differences in the mechanical response and failure behaviour.

\section{Conclusions}

The mechanical properties and failure characteristics of the $\mathrm{Cu}$-PTFE specimens prepared by different manufacturing methods were investigated through strain rate compression tests and SEM. The main conclusions drawn are as follows: 
(1) It is feasible to prepare Cu-PTFE composites via hotpress sintering. The densification of the specimen can reach $99.54 \%$, which is higher than that obtained by extrusion forming.

(2) Quasi-static uniaxial compression tests were performed on the specimens, and the strain rate effect was not observed in either type of specimen. The elastic modulus of the extruded Cu-PTFE was $54.6 \%$ higher than that of the hot-press sintered Cu-PTFE, while the yield strength was lower.

(3) The mechanical properties of hot-press sintered $\mathrm{Cu}$ PTFE are better than those of its extruded counterpart under dynamic impact; its yield and ultimate strengths are higher than those of the extruded samples by $42 \%$ and $51 \%$, respectively. In addition, the toughness of hot-press sintered Cu-PTFE requires more energy to produce the same failure form as extrudate $\mathrm{Cu}$-PTFE.

(4) The surface defects of Cu-PTFE prepared by extrusion are composed of cracks formed by the elastic mismatch between grains and large areas of plastic pores caused by pore polymerisation. Surface defects in hot-press sintered Cu-PTFE are caused by shear deformation and boundary sliding of the PTFE matrix. Particle pull-out was observed in the extruded specimen under dynamic compression, whereas matrix tearing appeared in the hot-press sintered specimen.

\section{Data Availability}

The data used to support the findings of this study are included within the article.

\section{Conflicts of Interest}

The authors declare no conflicts of interest.

\section{Acknowledgments}

This work was financially supported by the Fund Project of Science and Technology on Transient Impact Laboratory (Grant no. 6142606191105). The financial contributions are gratefully acknowledged.

\section{References}

[1] Y. J. Xu, Z. J. Wang, G. D. Wu, J. P. Yin, F. D. Dong, and Y. X. Jin, "Density effect of PTFE-Copper powder metallurgy liner material on the perforation performance of shaped charge jets," Strength of Materials, vol. 51, no. 4, pp. 616-623, 2019.

[2] J. P. Yin, B. B. Gao, Z. J. Wang, and C. L. Zhao, "A comparative study of damage performance of the kill element from different materials," Strength of Materials, vol. 49, no. 1, pp. 20-26, 2017.

[3] B. H. Chang, J. P. Yin, Z. Q. Cui, and T. X. Liu, "Numerical simulation of modified low-density jet penetrating shell charge," International Journal of Simulation Modelling, vol. 14, no. 3, pp. 426-437, 2015.
[4] L. Ding, W. Tang, and X. Ran, "Simulation study on jet formability and damage characteristics of a low-density material liner," Materials, vol. 11, no. 1, pp. 72-1, 2018.

[5] J. Borkowski, Z. Wilk, P. Koslik, L. Szymanczyk, and B. Zygmunt, "Application of sintered liners for explosively formed projectile charges," International Journal of Impact Engineering, vol. 118, pp. 91-97, 2018.

[6] N. Duan, Y. Gao, J. Wang, W. Du, and F. Wang, "The properties of the sintered copper powder liner," Journal of Wuhan University of Technology, vol. 29, no. 2, pp. 269-272, 2014.

[7] P. J. Rae and E. N. Brown, "The properties of poly(tetrafluoroethylene) (PTFE) in tension," Polymer, vol. 46, no. 19, pp. 8128-8140, 2005.

[8] P. J. Rae and D. M. Dattelbaum, "The properties of poly(tetrafluoroethylene) (PTFE) in compression," Polymer, vol. 45, no. 22, pp. 7615-7625, 2004.

[9] E. N. Brown, P. J. Rae, E. Bruce Orler, G. T. Gray III, and D. M. Dattelbaum, "The effect of crystallinity on the fracture of polytetrafluoroethylene (PTFE)," Materials Science and Engineering: C, vol. 26, no. 8, pp. 1338-1343, 2006.

[10] B. Poitou, F. Dore, and R. Champomier, "Mechanical and physical charactersations of polytetrafluoroethylene by high velocity compaction," International Journal of Material Forming, vol. 2, no. s1, pp. 657-660, 2009.

[11] Y. L. Li, J. P. Yin, and T. X. Liu, "Experimental study on mechanical properties of modified polytetrafluoroethylene," Journal of Measurement Science and Instrumentation, vol. 6, no. 4, pp. 390-395, 2015.

[12] D. Gu, L. Zhang, S. Chen, K. Song, and S. Liu, "Optimization of PTFE/Cu/Al2 O3 filled PMMA based composites on tribological properties using Taguchi design method," Journal of Applied Polymer Science, vol. 135, no. 45, p. 46705, 2018.

[13] S. Beckford, L. Mathurin, J. Chen, and M. Zou, "The influence of $\mathrm{Cu}$ nanoparticles on the tribological properties of polydopamine/PTFE + Cu films," Tribology Letters, vol. 59, no. 1, 1 page, 2015.

[14] T. Xie, Z. X. Xu, Z. M. Yan et al., "Study on the friction and wear behaviors of $\mathrm{Cu} / \mathrm{PTFE}$ self-lubricating composites," Applied Mechanics and Materials, vol. 130-134, pp. 14661469, 2012.

[15] G. T. I. Gray, W. R. Blumenthal, C. P. Trujillo, and R. W. I. Carpenter, "Influence of temperature and strain rate on the mechanical behavior of adiprene L-100," Journal De Physique IV, vol. 07, no. C3, pp. 523-528, 1997.

[16] G. T. Gray, High-Strain-Rate Testing of Materials: The SplitHopkinson Pressure Bar, John Wiley \& Sons, New York, NY, USA, 2012.

[17] J. L. Jordan, C. R. Siviour, J. R. Foley, and E. N. Brown, "Compressive properties of extruded polytetrafluoroethylene," Polymer, vol. 48, no. 14, pp. 4184-4195, 2007.

[18] B. Feng, X. Fang, H.-X. Wang, W. Dong, and Y.-C. Li, "The effect of crystallinity on compressive properties of Al-PTFE," Polymers, vol. 8, no. 10, pp. 356-10, 2016. 